\title{
Overexpression of Fli-1 in astrocytoma is associated with poor prognosis
}

\author{
Hung-Pei Tsai ${ }^{1}$, Tai-Hsin Tsai ${ }^{2,3}$, Ya-Ju Hsieh ${ }^{4}$, Yi-Ting Chen $^{5}$, Chih-Ling Lee $^{5}$, Yi- \\ Cheng Tsai ${ }^{1}$, Ting-Chang She ${ }^{5}$, Chih-Lung Lin ${ }^{2,3}$, Chee-Yin Chai ${ }^{5,6,7}$, Aij-Lie Kwan ${ }^{2,3,8}$ \\ ${ }^{1}$ Graduate Institute of Medicine, College of Medicine, Kaohsiung Medical University, Kaohsiung, Taiwan \\ ${ }^{2}$ Division of Neurosurgery, Department of Surgery, Kaohsiung Medical University Hospital, Kaohsiung, Taiwan \\ ${ }^{3}$ Department of Surgery, Faculty of Medicine, College of Medicine, Kaohsiung Medical University, Kaohsiung, Taiwan \\ ${ }^{4}$ Department of Medical Imaging and Radiological Sciences, Kaohsiung Medical University, Kaohsiung, Taiwan \\ ${ }^{5}$ Department of Pathology, Kaohsiung Medical University Hospital, Kaohsiung, Taiwan \\ ${ }^{6}$ Department of Pathology, College of Medicine, Kaohsiung Medical University, Kaohsiung, Taiwan \\ ${ }^{7}$ Institute of Biomedical Sciences, National Sun Yat-Sen University, Kaohsiung, Taiwan \\ ${ }^{8}$ Department of Neurosurgery, University of Virginia, Charlottesville, VA, USA \\ Correspondence to: Aij-Lie Kwan, email: a_lkwan@yahoo.com \\ Chee-Yin Chai, email: ccjtsai@yahoo.com
}

Keywords: astrocytoma, Fli-1, prognostic marker

Received: June 29, 2016 Accepted: February 20, $2017 \quad$ Published: March 16, 2017

Copyright: Tsai et al. This is an open-access article distributed under the terms of the Creative Commons Attribution License (CC-BY), which permits unrestricted use, distribution, and reproduction in any medium, provided the original author and source are credited.

\section{ABSTRACT}

Background: Astrocytoma, a common and highly malignant type of brain tumor, is associated with poor overall survival despite advances in surgical treatment, radiotherapy, and chemotherapy. The nuclear transcription factor Fli-1 has been shown to increase cellular proliferation and tumorigenesis in many types of cancer; however, previous reports have not described a correlation between clinical outcomes and Fli-1 in astrocytoma patients. The present study aimed to elucidate the clinical role of Fli-1 in astrocytoma.

Results: High-level of Fli-1 protein expression was significantly association with World Health Organization (WHO) high grade and poor prognosis. A multivariate analysis revealed that the WHO grade and Fli-1 protein expression were independent factor of prognostic factors of patients with astrocytoma. In addition, Fli-1 silencing inhibited proliferation, migration, and invasion and led to the downregulation of Ki67, VEGF, and cyclin D1 expression in the astrocytoma cells.

Materials and methods: Fli-1 protein expression in astrocytoma tissue samples were detected via immunohistochemistry, and potential correlations between clinical parameters and Fli-1 expression were assessed in patients with astrocytoma. Additionally, proliferation, invasion, and migration assays of astrocytoma cell lines were conducted to evaluate the effects of short interfering RNA (siRNA) on these processes; in addition, these cells were subjected to western blotting to detect the expression levels of Fli-1, Ki-67, VEGF, and Cyclin D1.

Conclusion: Fli-1 shows promise as a potential prognostic biomarker and therapeutic molecular target for astrocytoma patients.

\section{INTRODUCTION}

Astrocytoma is a common type of brain tumor in humans. According to the World Health Organization
(WHO), astrocytomas can be classified into four grades [1]. Grade I astrocytomas, such as pilocytic astrocytomas, are benign and slow-growing, and grade II astrocytomas comprise relatively slow-growing diffuse tumors. 
However, grade III and grade IV tumors, exemplified by anaplastic astrocytoma and glioblastoma, respectively, are highly malignant. Grade III astrocytomas exhibit mitotic histopathology. Grade IV astrocytoma or glioblastoma is the most aggressive human malignant primary brain tumor and is characterized by histopathologic features, such as vascular thrombosis, microvascular proliferation, or necrosis. Despite advances in surgical treatment, radiotherapy, and chemotherapy, the overall survival of glioblastoma patients remains poor. Specifically, patients with a diagnosis of glioblastoma have the median survival period of only $12-15$ months, with only $10 \%$ of the patients surviving 5 years [2] and a median survival of merely 3-4 months without treatment [3].

In humans, friend leukemia integration 1 transcription factor (Fli-1), also known as transcription factor ERGB, is encoded by the Fli-1 gene, a proto-oncogene and features a 98-amino-acid DNA binding domain $[4,5]$. The Ewing sarcoma $\mathrm{t}(11 ; 22)(\mathrm{q} 24 ; \mathrm{q} 12)$ translocation substitutes a putative RNA-binding domain of the Ewing sarcoma gene (EWS) on chromosome 22 for the DNA-binding domainencoding region of FLI-1 on chromosome 11 to yield a chimeric transcription factor that requires the DNA binding domain encoded by FLI-1 for transformation. Fli-1, a member of the ETS transcription factor family, is also the target of insertional activation by Friend murine leukemia virus (F-MuLV) and is preferentially expressed in vascular endothelial cells and hematopoietic tissues [6]. ETS family transcription factors regulate the expression of oncogenes, tumor suppressor genes, and other genes related to vessel formation, invasion, and metastasis, and expression of these factors often correlates with poor survival [7-10].

Fli-1 affects cellular proliferation and tumorigenesis in Ewing sarcoma and primitive neuroectodermal tumors $[11,12]$., and additionally plays critical roles in normal development, hematopoiesis, and oncogenesis through its dual functions as a transcriptional activator and repressor
[13-17]. Previous studies have shown that knockingdown Fli-1 leads to marked growth inhibition and death in erythroleukemic cells, indicating a possible use of Fli-1 as a therapeutic target to induce tumor suppression [18-20]. Other studies identified Fli-1 overexpression as a biomarker of certain cancers including melanoma [21], ovarian cancer [22], endometrial cancer [23], breast cancer [24], and nasopharyngeal carcinoma (NPC) [25]. However, no previous studies have identified a correlation between Fli1 protein expression and the clinical parameters associated with astrocytoma. Therefore, the present study aimed to validate the clinical role of Fli-1 in patients with astrocytoma.

\section{RESULTS}

\section{Correlations between Fli-1 expression and clinical parameters}

Of the 108 astrocytoma patients included in the study, 27 and 81 were $>60$ years and $\leq 60$ years, respectively. In addition, 28 and 80 patients had grade II and III/IV astrocytoma, respectively, according to the WHO classification, and 74 and 34 cases had a Karnofsky performance score (KPS) of $\leq 70$ and $>70$, respectively. Figure 1 presents examples of immunohistochemically stained sections exhibiting low and high levels of nuclear Fli-1. Chi-square analysis revealed a significant association between Fli-1 expression and the WHO grade $(P<0.001$; Table 1$)$.

\section{Survival analysis}

A Kaplan-Meier analysis and subsequent log-rank analysis confirmed the correlation between Fli-1 expression and survival in astrocytoma patients; specifically, a high level of Fli-1 expression correlated significantly with poor overall survival $(P<0.001$; Figure $2 \mathrm{~A})$. In low

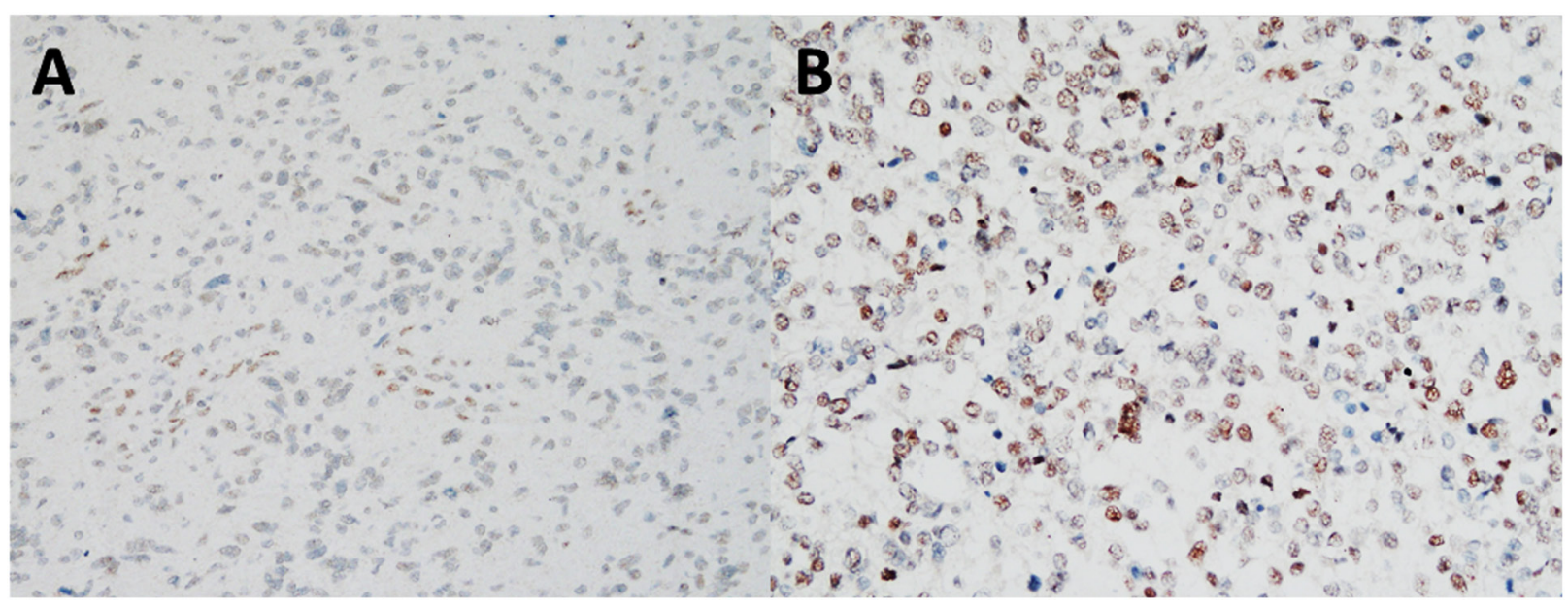

Figure 1: Representative results of immunohistochemical staining for Fli-1, using samples obtained from astrocytoma patients with different scores. (A) Astrocytoma without or with weak Fli-1 expression (score: 1-3). (B) Astrocytoma with moderate or strong Fli-1 expression (score: 4-9). Magnification, 100X. 
Table 1: Correlation of Fli-1 expression with clinicopathologic parameters in patients with astrocytoma

\begin{tabular}{|c|c|c|c|c|}
\hline & \multirow{2}{*}{ No. of patients } & \multicolumn{2}{|c|}{ Fli-1 expression (n, \%) } & \multirow{2}{*}{$P$-value } \\
\hline & & Low & High & \\
\hline Age (years) & & & & 0.801 \\
\hline$>60$ & 27 & $6(5.6 \%)$ & $21(19.4 \%)$ & \\
\hline$\leq 60$ & 81 & $22(20.4 \%)$ & $59(54.6 \%)$ & \\
\hline Sex & & & & 1 \\
\hline Male & 61 & $16(14.8 \%)$ & $45(41.7 \%)$ & \\
\hline Female & 47 & $12(11.1 \%)$ & $35(32.4 \%)$ & \\
\hline WHO Grade & & & & $<0.001$ \\
\hline II & 28 & $18(16.7 \%)$ & $10(9.3 \%)$ & \\
\hline III/IV & 80 & $10(9.3 \%)$ & $70(64.8 \%)$ & \\
\hline Tumor size & & & & 0651 \\
\hline$\leq 3 \mathrm{~cm}$ & 68 & $19(17.6 \%)$ & $49(45.4 \%)$ & \\
\hline$>3 \mathrm{~cm}$ & 40 & $9(8.3 \%)$ & $31(28.7 \%)$ & \\
\hline KPS & & & & 0.159 \\
\hline$\leq 70$ & 74 & $16(14.8 \%)$ & $58(53.7 \%)$ & \\
\hline$>70$ & 34 & $12(11.1 \%)$ & $22(20.4 \%)$ & \\
\hline
\end{tabular}

* Statistical significance $(P<0.05)$.

WHO, World Health Organization; KPS, Karnofsky performance score.

A

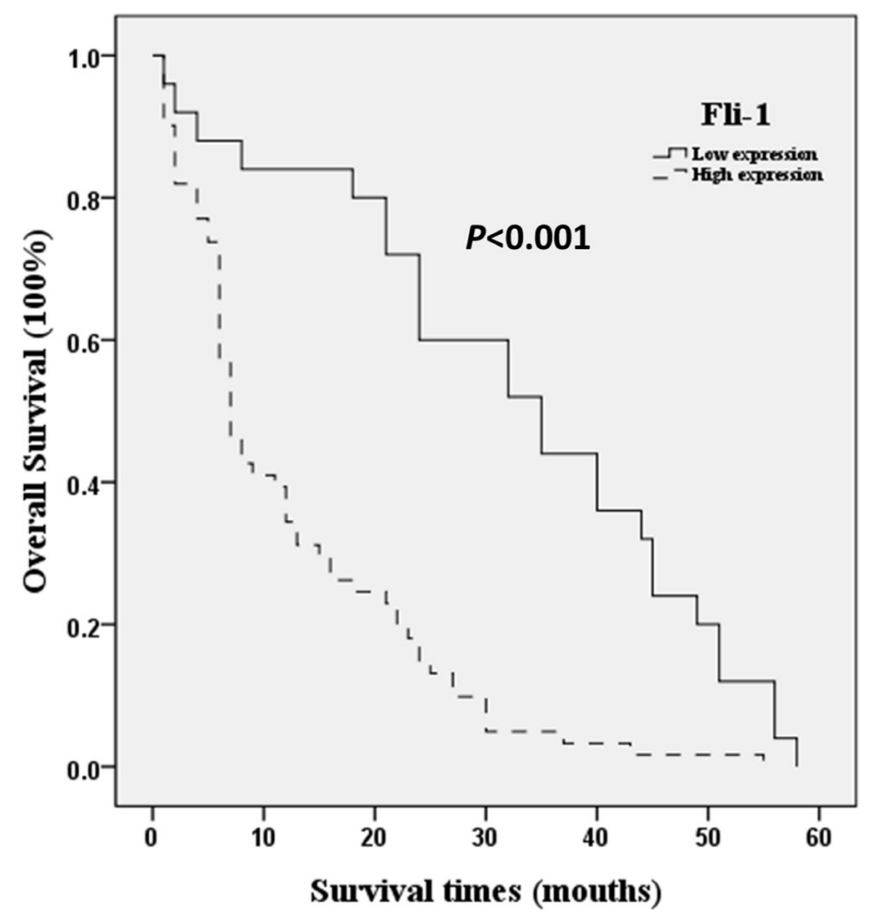

B

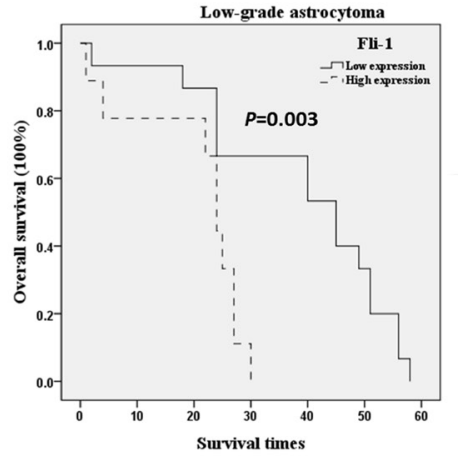

C

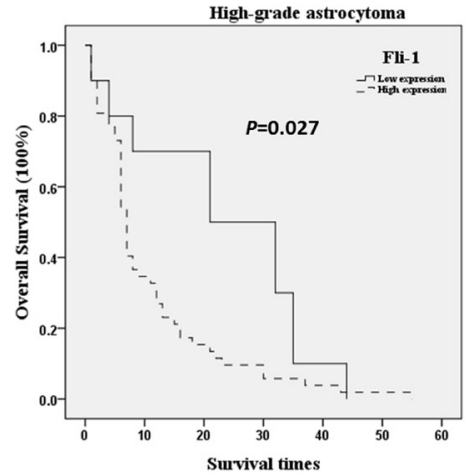

Figure 2: Kaplan-Meier analysis of overall patient survival according to Fli-1 expression. Significance was determined using the log-rank test. (A) All astrocytoma patients. (B) Low-grade astrocytoma patients (C) High-grade astrocytoma patients. 
Table 2: Univariate and multivariate Cox regression analyses of prognostic parameters in patients with astrocytoma

\begin{tabular}{|c|c|c|c|c|c|c|}
\hline \multicolumn{4}{|c|}{ Univariate analysis } & \multicolumn{3}{|c|}{ Multivariate analysis } \\
\hline & Relative risk & $95 \% \mathrm{CI}$ & $P$ & Relative risk & $95 \% \mathrm{CI}$ & $P$ \\
\hline Age & 0.866 & $0.503-1.492$ & 0.605 & & & \\
\hline Sex & 1.069 & $0.668-1.710$ & 0.782 & & & \\
\hline WHO grade & 0.365 & $0.203-0.656$ & 0.001 & 0.475 & $0.267-0.846$ & 0.011 \\
\hline Tumor size & 1.253 & $0.776-2.024$ & 0.357 & & & \\
\hline KPS & 1.491 & $0.882-2.521$ & 0.136 & & & \\
\hline Fli-1 expression & 0.369 & $0.207-0.659$ & 0.001 & 0.401 & $0.225-0.714$ & 0.002 \\
\hline
\end{tabular}

* Statistical significance $(P<0.05)$.

CI, confidence interval; WHO, World Health Organization; KPS, Karnofsky performance score.

grade (WHO grade II) astrocytoma, a high level of Fli1 expression correlated significantly with poor overall survival ( $P=0.003$; Figure $2 \mathrm{~B})$. In high grade (WHO grade III/VI) astrocytoma, a high level of Fli-1 expression correlated significantly with poor overall survival $(P=$ 0.027; Figure 2C). A univariate analysis identified the WHO grade $(P=0.001)$ and Fli-1 expression $(P=0.001)$ as factors significantly associated with prognosis. The multivariate Cox regression analysis further identified the WHO grade (hazard ratio [HR], 0.475; 95\% confidence interval, $0.267-0.846 ; P=0.011)$ and Fli-1 protein expression (HR, 0.401 ; 95\% confidence interval, 0.225 $0.714 ; P=0.002$ ) as independent factors associated with prognosis in astrocytoma patients (Table 2).

\section{Elevated Fli-1 protein expression in astrocytoma cells relative to normal cells}

The levels of Fli-1 expression in the glia cell line SVGq12 and astrocytoma cell lines GBM8401, GBM8901, U87MG, and G5T were analyzed via western blotting. GBM8401 $(P<0.001)$, GBM8401 $(P<0.001)$, U87MG $(P<0.001)$, and G5T $(P=0.041)$ expressed significantly higher levels of Fli-1 protein, compared with SVGq12 (Figure 3). The cellular localization of Fli-1 was evaluated in astrocytoma cells. Cellular fractionation was verified by the presence of Lamin $\mathrm{A} / \mathrm{C}$ and $\gamma$-tubulin in the nuclear and cytoplasmic fractions, respectively. Notably, Fli-1 was present in the nuclear fraction (Figure 4). In addition, GBM8401 cells and U87MG cells were subjected to siRNA-induced knockdown of Fli-1. After a 48-h incubation with Fli-1 siRNA (si-Fli-1 group) or nonsense siRNA (si-non group), Fli-1 protein expression levels were compared between the control /si-non groups and siRNA group via western blotting. In GBM8401 cells, western blotting revealed that Fli-1 knockdown decreased protein expression of Fli-1 with si-Fli-1 \#1 $(P$ $=0.004)$ or si-Fli-1 \#2 $(P=0.028)$ (Figure $5 \mathrm{~A}$ and $5 \mathrm{C})$.
However, in U87MG cells, western blotting revealed that Fli-1 knockdown decreased protein expression of Fli-1 with si-Fli-1 \#1 ( $P=0.009)$, but not with si-Fli-1 \#2 (Figure 5B and 5D). The results indicated that Fli-1 knockdown successfully downregulated the expression of Fli-1 protein, as intended, and revealed no significant differences between the control group and si-non group.

\section{Fli-1 knockdown attenuated astrocytoma cell proliferation}

To evaluate Fli-1 siRNA treatment on proliferation, we used a MTT assay to detect GBM8401 cells and $\mathrm{U} 87 \mathrm{MG}$ cells proliferation and compared the results of the si-Fli-1. After 24-h, 48-h, and 72-h incubation with siRNA, cell viability was assayed via MTT assay. In GBM8401 cells, the results indicated reduced cell viability in the si-Fli-1 \#1 $(P=0.006)$ and si-Fli-1 \#2 $(P=0.035)$ group relative to the control on 48 hours, and the reduced cell viability in the si-Fli-1 $\# 1$ group $(P=0.008)$ and siFli-1 \#2 group $(P=0.025)$ relative to the control on 72 hours (Figure 6A). In U87MG cells, the results indicated reduced cell viability in the si-Fli-1 $\# 1$ group $(P=0.048)$ relative to the control on 48 hours, and the reduced cell viability in the si-Fli-1 $\# 1$ group $(P=0.005)$ and si-Fli-1 \#2 group $(P=0.049)$ relative to the control on 72 hours (Figure 6B). However, no differences were found between the control and si-non groups in GBM8401 cells and U87MG cells. These data indicate a correlation between Fli-1 knockdown and reduced cell viability in astrocytoma cells.

\section{Fli-1 knockdown inhibited astrocytoma cell migration}

To evaluate cell migration, we used a wound healing assay and compared between control group and si-Fli-1 group. In GBM8401 cells, si-RNA-induced Fli-1 
A

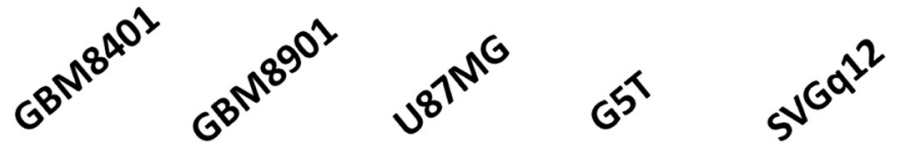

Fli-1

\section{$\beta$-actin}

B

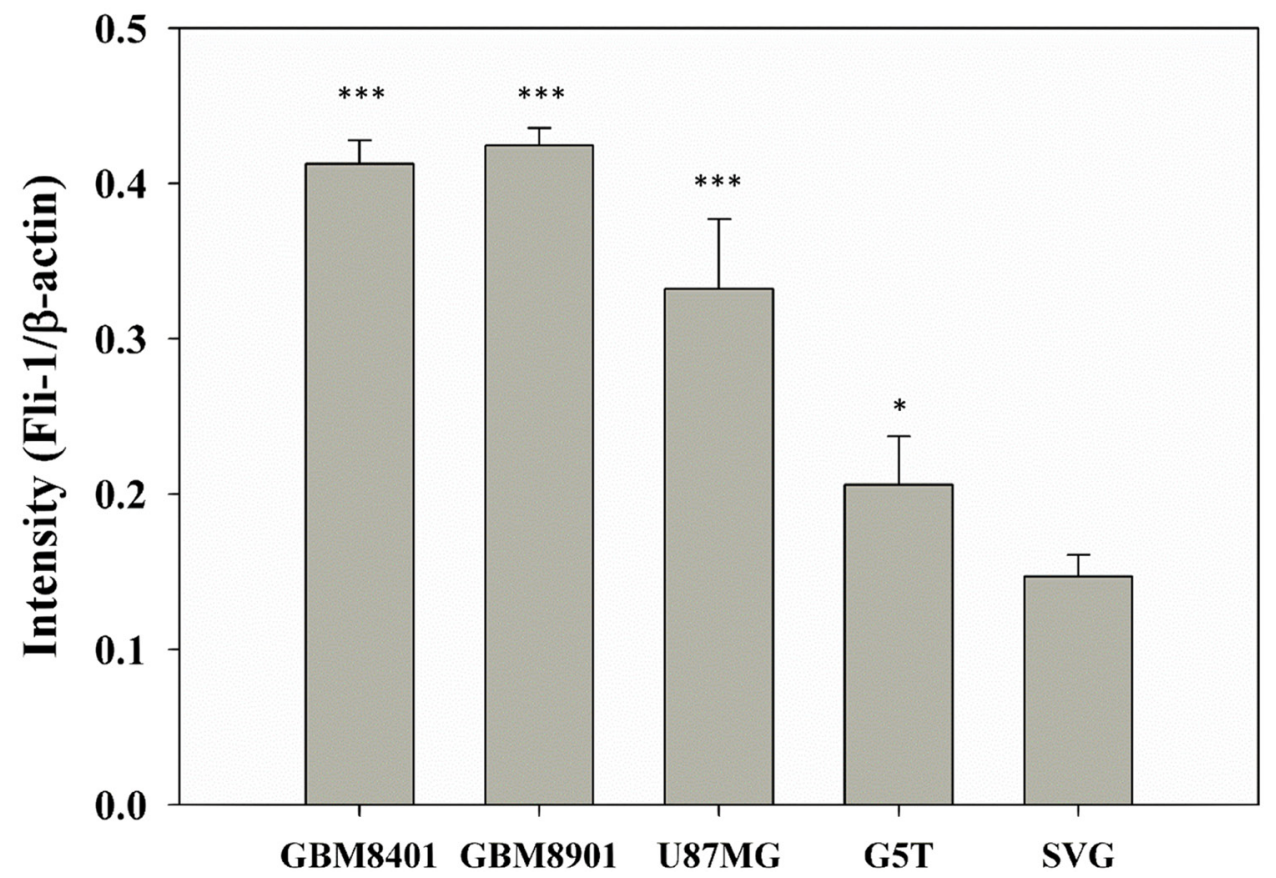

Figure 3: Fli-1 protein expression in all tested astrocytoma cell lines. (A) Western blot of Fli-1. (B) Relative Fli-1 protein expression levels $(* P<0.05, * * * P<0.001$ vs. SVGq12).
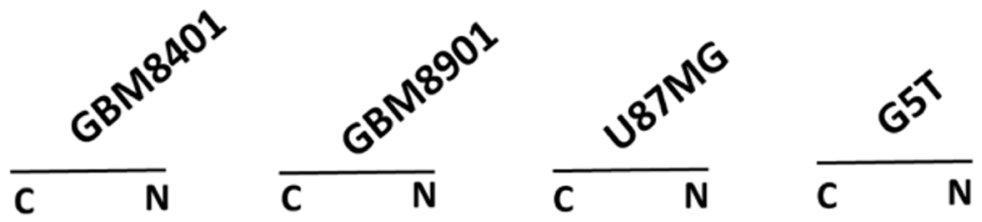

Fli-1

\section{Lamina A/C}

\section{v-tubulin}

Figure 4: Western blots showing the Fli-1 protein of the isolated nucleus/cytoplasm sample, nuclear (N) and cytoplasmic (C). 
knockdown with si-Fli1 \#1 $(P<0.001)$ and si-Fli-1 \#2 $(P$ $=0.002)$ markedly inhibited the migratory capability at 12 hours, and knockdown of Fli-1 with si-Fli-1 \#1 $(P<0.001)$ and si-Fli-1 \#2 ( $P=0.004)$ markedly inhibited the migratory capabilities at 24 hours (Figure 7A-7M). In U87MG cells, si-RNA-induced Fli-1 knockdown with si-Fli1 \#1 $(P$ $=0.003)$ and si-Fli-1 \#2 $(P=0.004)$ markedly inhibited the migratory capabilities at 12 hours, and knockdown of Fli1 with si-Fli1 \#1 $(P<0.001)$ and si-Fli-1 \#2 $(P<0.001)$ markedly inhibited the migratory capability at 24 hours (Figure 7N-7Z). These data suggest that knockdown of Fli-1 inhibit migration in astrocytoma cells.

A

GBM8401

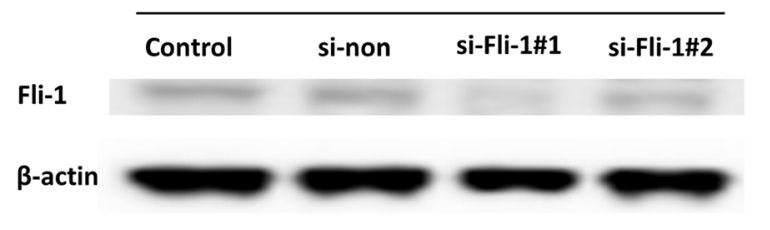

C

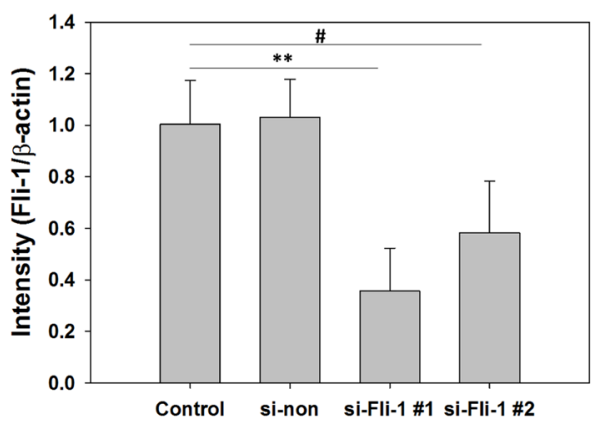

\section{Fli-1 knockdown inhibited astrocytoma cell invasion}

To evaluate cell invasion, we used a Matrigel invasion assay and compared between control group and si-Fli-1 group. In GBM8401 cells, si-RNA-induced Fli-1 knockdown with si-Fli1 \#1 $(P=0.001)$ and si-Fli-1 \#2 $(P=0.011)$ markedly inhibited the invasive capability (Figure 8A-8E). In U87MG cells, si-RNA-induced Fli-1 knockdown with si-Fli1 \#1 $(P<0.001)$ and si-Fli-1 \#2 $(P<0.001)$ markedly inhibited the invasive capability (Figure $8 \mathrm{~F}-8 \mathrm{~J}$ ). These data suggest that knockdown of Fli-1 inhibit invasion in astrocytoma cells.

B

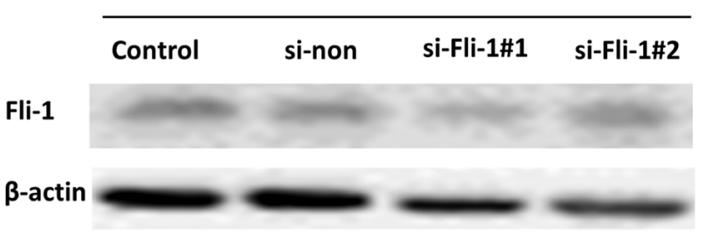

D

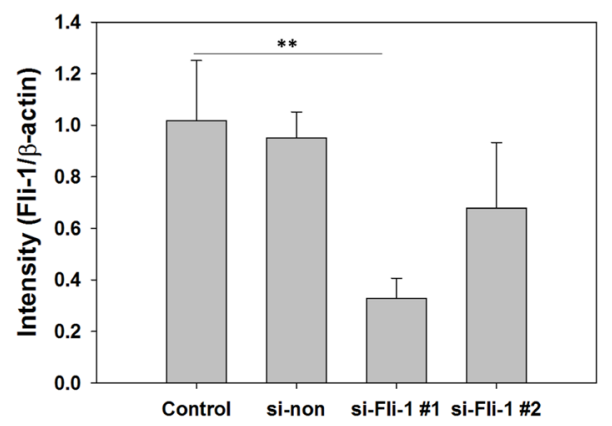

Figure 5: Comparison of Fli-1 expression in control, non-siRNA-treated, and Fli-1 siRNA-treated astrocytoma cells. (A) Western blot of Fli-1 in GBM8401 cells. (B) Western blot of Fli-1 in U87MG cells. (C) Relative Fli-1 protein expression levels in GBM8401 cells. (D) Relative Fli-1 protein expression levels in U87MG cells $(* P<0.05, * * P<0.01$, and $* * * P<0.001$ compared with si-Fli-1 \#1; ${ }^{\#} P<0.05,{ }^{\#} P<0.01$, and ${ }^{\# \#} P<0.001$ compared with si-Fli-1 \#2).

A

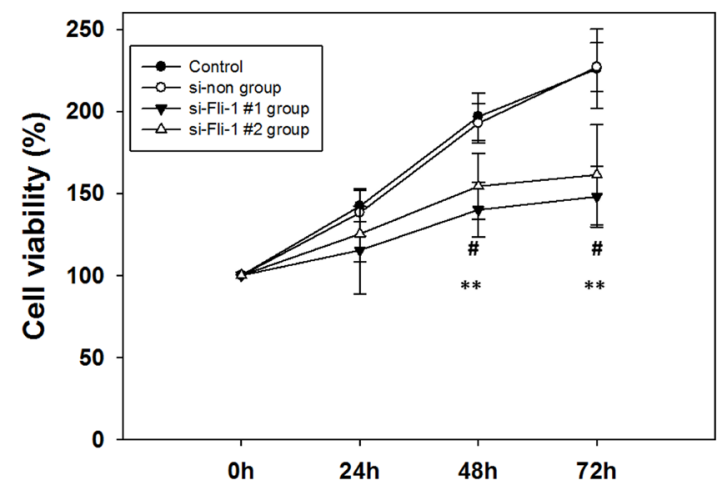

B

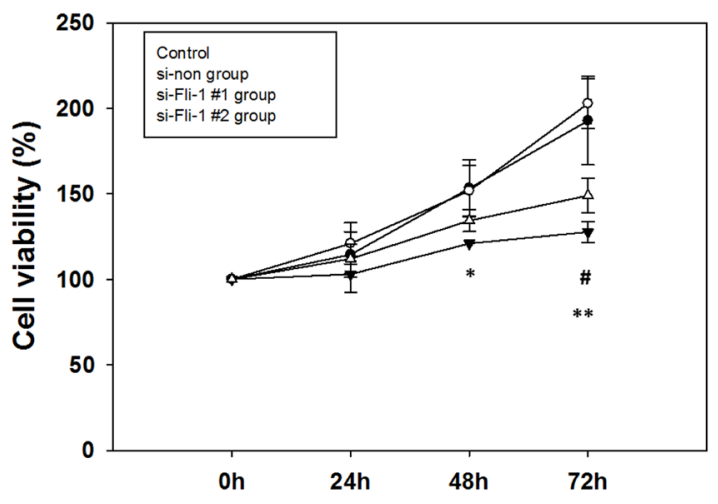

Figure 6: Cell viability analysis of Fli-1 siRNA-transfected (A) GBM8401 cells and (B) U87MG cells cultured for 24h, 48h, and 72h in 6-well plates. $\left({ }^{*} P<0.05,{ }^{* *} P<0.01\right.$, and ${ }^{* * *} P<0.001$ compared with si-Fli-1 ${ }^{\# 1} ;{ }^{\#} P<0.05,{ }^{\# *} P<0.01$, and ${ }^{\# \# \#} P<$ 0.001 compared with si-Fli-1 \#2). 


\section{Effect of Fli-1 knockdown on Ki-67, cyclin D1, and vascular endothelial growth factor (VEGF) protein expression}

To evaluate the expression of proteins related to cell proliferation and migration, a western blot analysis of Ki-67, VEGF, and cyclin D1 was conducted. Ki-67 and cyclin D1 are markers of astrocytoma malignancy, and VEGF is a marker of angiogenesis. In GBM8401 cells, western blotting revealed that Fli-1 knockdown led to the downregulation of Ki-67 $(P<0.001)$, cyclin D1 expression $(P=0.001)$, and VEGF expression $(P<0.001)$ with siFli-1 \#1 and the downregulation of Ki-67 $(P=0.001)$, cyclin D1 expression $(P=0.019)$, and VEGF expression $(P$ $<0.001$ ) with si-Fli-1 \#2 (Figure 9A-9D). In U87MG cells, western blotting revealed that Fli-1 knockdown led to the downregulation of Ki-67 $(P<0.001)$, cyclin D1 expression $(P=0.002)$, and VEGF expression $(P=0.003)$ with siFli-1 \#1 and the downregulation of Ki-67 $(P<0.001)$, cyclin D1 expression $(P=0.011)$, and VEGF expression $(P=0.023)$ with si-Fli-1 \#2 (Figure 9E-9H). These data suggest that knockdown of Fli-1 decreased Ki-67, cyclin D1, and VEGF protein expression in astrocytoma cells.

\section{DISCUSSION}

The potential oncogenic nature of Fli-1 was previously demonstrated in erythroblastic leukemia, wherein Fli-1 was shown to induce the proliferation of

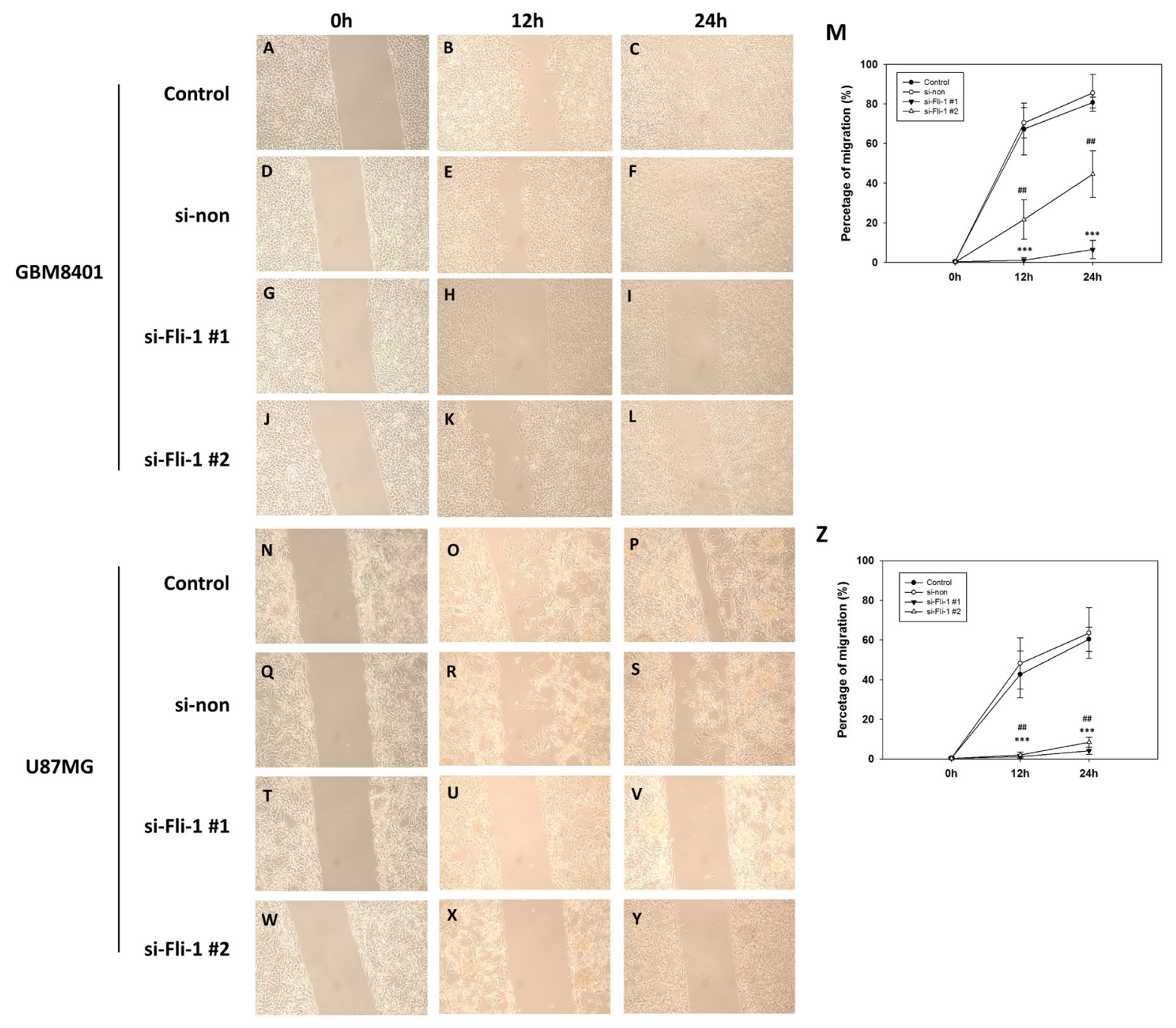

Figure 7: Wound healing analysis of GBM8401 cells and U87MG cells transfected with Fli-1 siRNA at 0, 12, and 24 hours after monolayer injury. Representative GBM8401 cells images from the (A-C) control group, (D-F) non-siRNA group (sinon), (G-I) si-Fli-1 \#1 group, and (J-L) si-Fli-1 \#2 group. (M) The percentage of migration. Representative U87MG cells images from the (N-P) control group, (Q-S) non-siRNA group (si-non), (T-V) si-Fli-1 \#1 group, and (W-Y) si-Fli-1 \#2 group. (Z) The percentage of migration. $\left({ }^{*} P<0.05,{ }^{* *} P<0.01\right.$, and ${ }^{* * *} P<0.001$ compared with si-Fli-1 $\# 1 ;{ }^{\#} P<0.05$, ${ }^{\#} P<0.01$, and ${ }^{\# \# \#} P<0.001$ compared with si-Fli-1 \#2). 
differentiation-arrested erythroblasts with longer survival of Fli-1 expressing with BCL2 expression [26]. In a previous study of malignant melanoma, Fli-1 expression was found to be associated with a higher proliferation rate of neoplastic cells. Fli-1 expression was also detected in Merkel cell carcinoma. Fli-1 expression was negative in the control group, increased in early-stage tumors, and reached a highest level in advanced-stage tumors. Clinicopathologic analysis of Fli-1 expression revealed positive correlations of high Fli-1 expression with an advanced tumor stage and positive lymph nodal involvement. Patients expressing high levels of Fli-1 had poor overall and disease-free survival outcomes. Taken together, these findings suggest that Fli-1 is an attractive candidate for risk prognostication and targeted therapy of EOC [22]. Moreover, Fli-1 expression was associated with poorer overall survival, DMFS, and progression-free survival and was confirmed as an independent prognostic factor in a multivariate analysis of NPC [25].

In the present study, a high Fli-1 expression level was associated with poor prognosis and a high WHO grade in patients with astrocytoma; in other words, Fli1 expression associates strongly with survival in this patient population. Increasing expression of Fli-1 is associated with tumor development and may possibly with malignancy. In a previous study, Fli-1 knockdown reduced ovarian cancer cell proliferation but did not affect tumor metastasis [22]. However, in our study, Fli-1 siRNA-mediated knockdown inhibited the proliferative, migration, and invasion abilities of astrocytoma cells.

Previous studies have reported that Fli-1 was predominantly expressed in the nuclei of Ewing sarcoma and leukemia cells [27], whereas other studies of ovarian cancer tissues and SKOV3 cells reported mainly cytoplasmic expression of Fli-1 [22]. In our study, Fli1 was detected in the nuclei of astrocytoma tissues, as well as GBM8401, GBM8901, U87-MG, and G5T cells. These data suggest that Fli-1 plays an essential nuclear role in astrocytomas. Moreover, previous studies support a potential function of Fli-1 through protein-protein interactions or as a nuclear transcription factor involved in cellular proliferation and tumorigenesis [17, 18, 28, 29].

The role of Fli-1 has been investigated in Ewing sarcoma and primitive neuroectodermal tumors; this potential role is implicated by the presence of a specific translocation $\mathrm{t}(11 ; 22)$ that resulting in a fusion of $E W S$ on chromosome 22 to FLII on chromosome 11 in $90 \%$ of cases of these tumors $[11,12]$. Further speculation suggests that Fli-1 is widely expressed in various cancer tissues but plays different, tissue-specific roles. For example, angiogenesis is required to provide proliferating tumor cells with nutrients and metabolites, and tumor

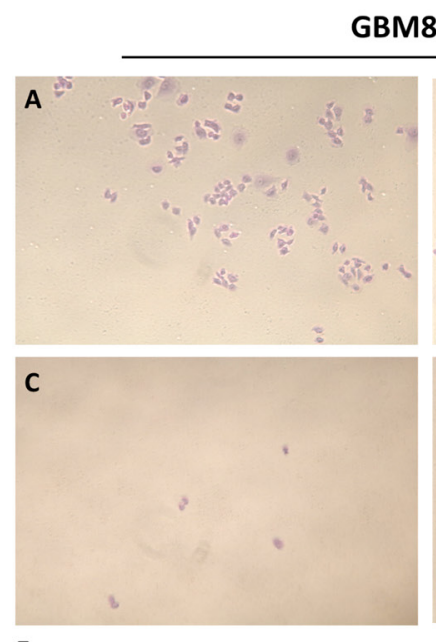

BM8401
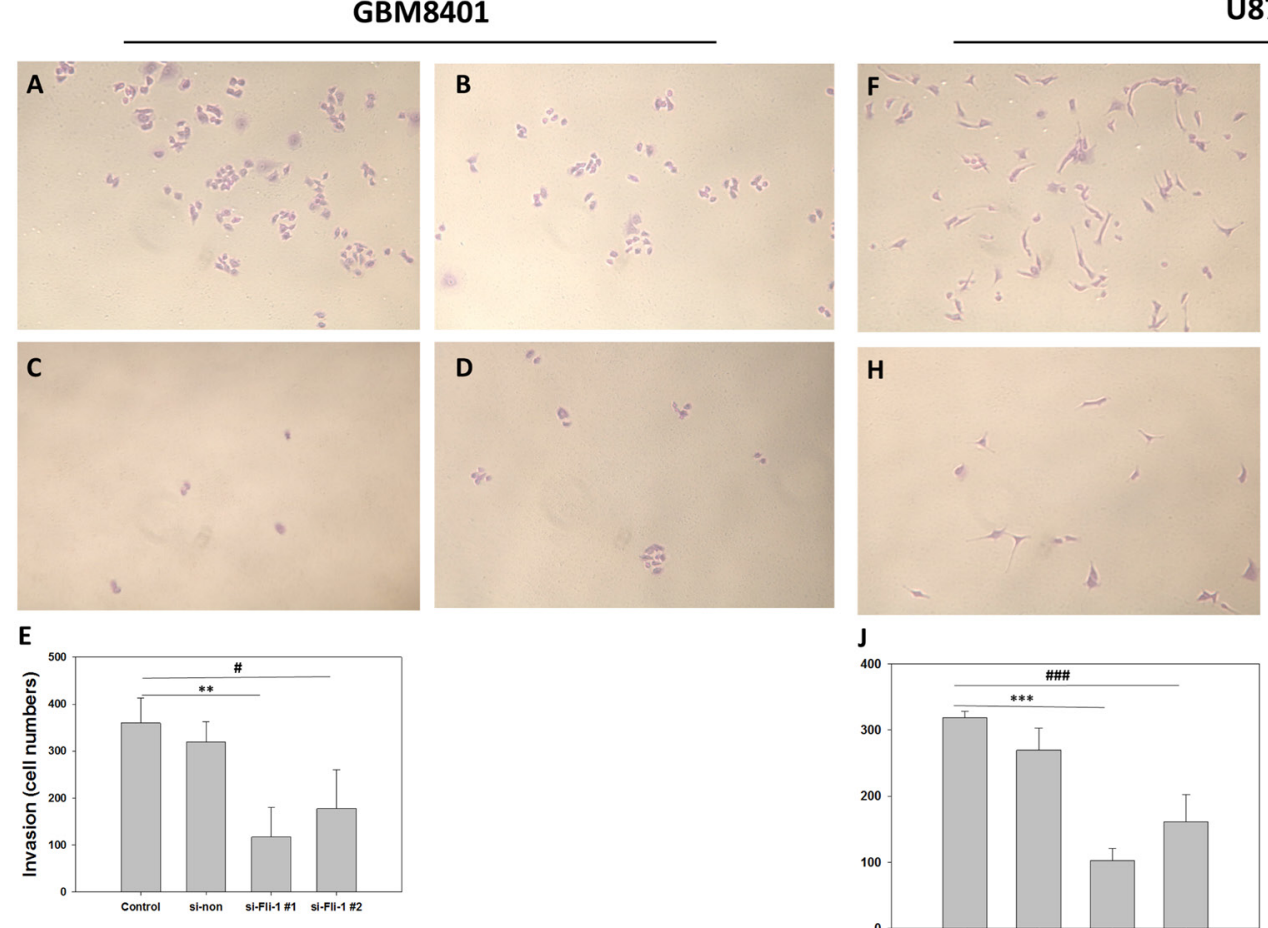

\section{U87MG}
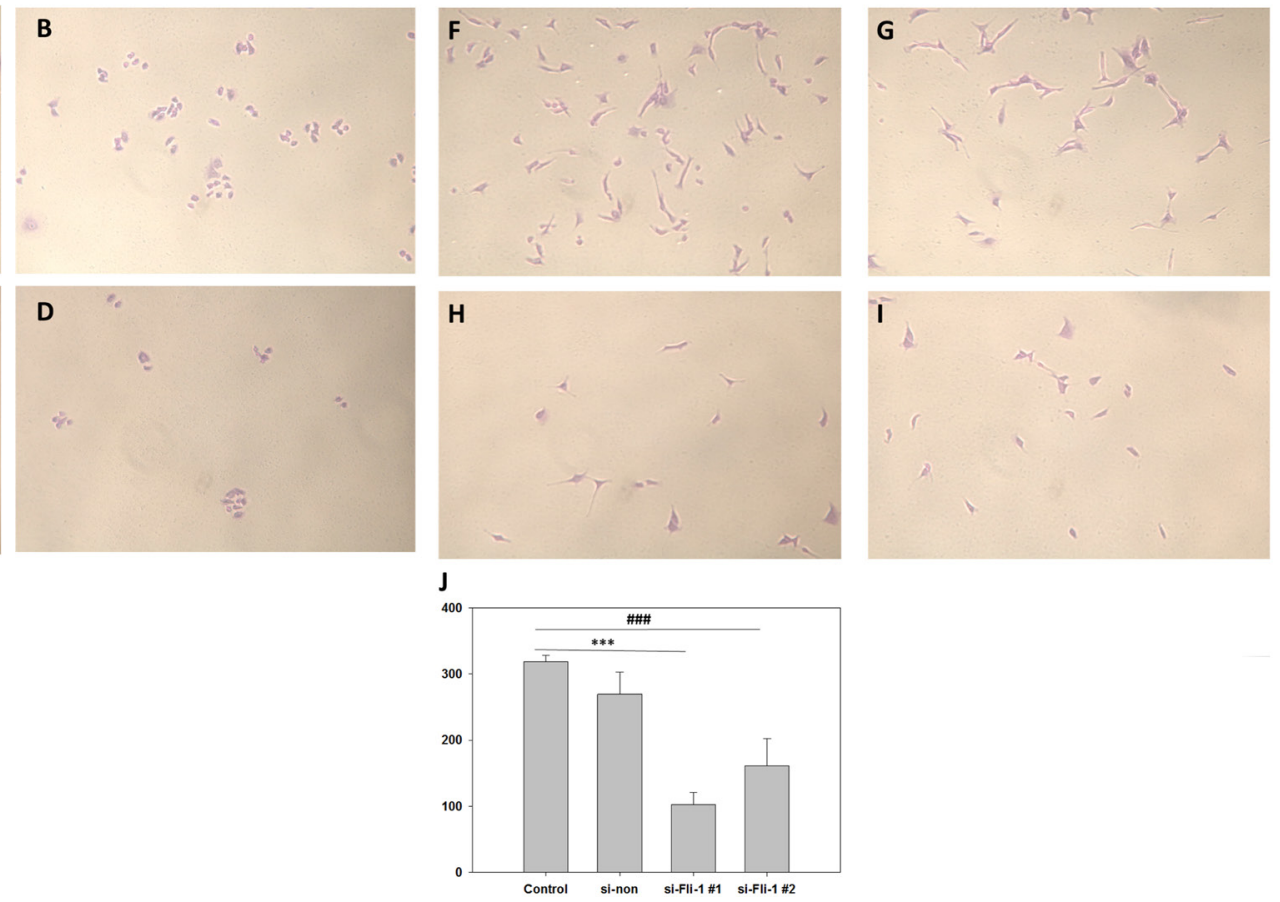

Figure 8: Single-day Transwell invasion analysis of GBM8401 cells and U87MG cells transfected with Fli-1 siRNA. Representative GBM8401 cells images from the (A) control group, (B) non-siRNA group (si-non), (C) si-Fli-1 \#1 group, and (D) si-Fli-1 \#1 group. (E) The number of invaded cells $(* * * P<0.001)$. Representative U87MG cells images from the (F) control group, (G) non-siRNA group (si-non), (H) si-Fli-1 \#1 group, and (I) si-Fli-1 \#1 group. (J) The number of invaded cells $(* * * P<0.001) .(* P<0.05, * * P<0.01$, and $* * * P<0.001$ compared with si-Fli-1 $\# 1$; ${ }^{\#} P<0.05,{ }^{\#} P<0.01$, and ${ }^{\# \#} P<0.001$ compared with si-Fli-1 \#2). 
cells regulate angiogenesis by secreting factors that stimulate neovascularization. Epithelial cells have been reported to express high levels of Fli-1 [30], a feature that has also been observed in the majority of benign and malignant vascular tumors [31-33]. The EWS-Fli-1 fusion protein directly activates VEGF-A, leading to increased angiogenesis and malignant progression [34]. High-levels of VEGF, which plays a critical role in tumor initiation, have also been detected in the tumor microenvironments of Fli-1-overexpressing erythroleukemias [35]. These results indicate the potential usefulness of Fli-1 as a biomarker of angiogenesis.

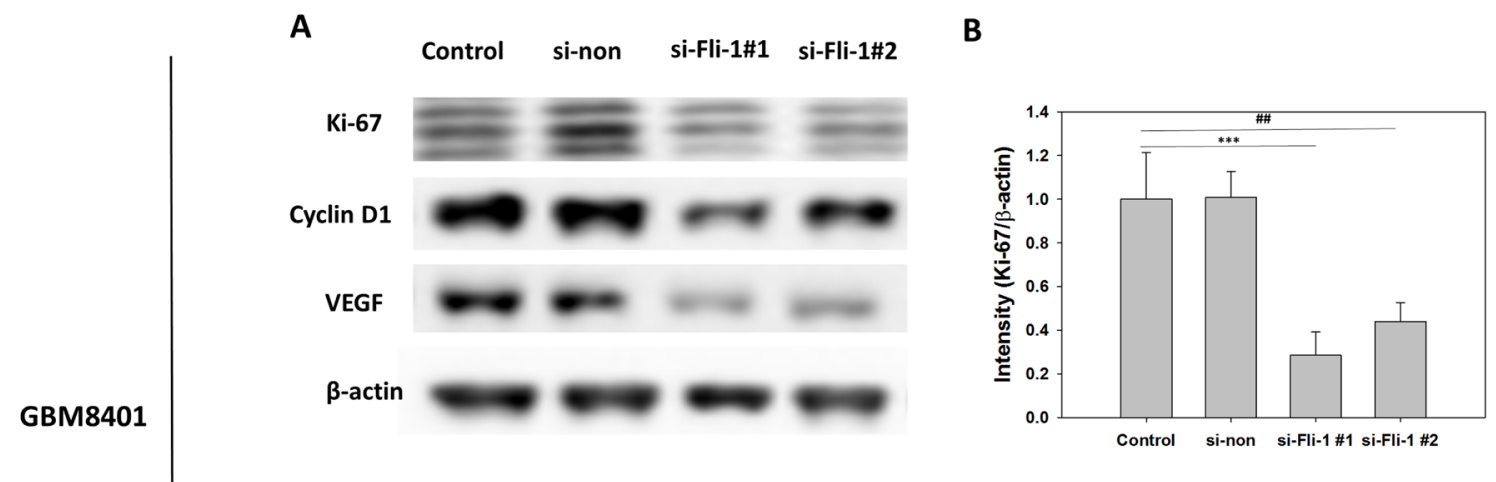

C
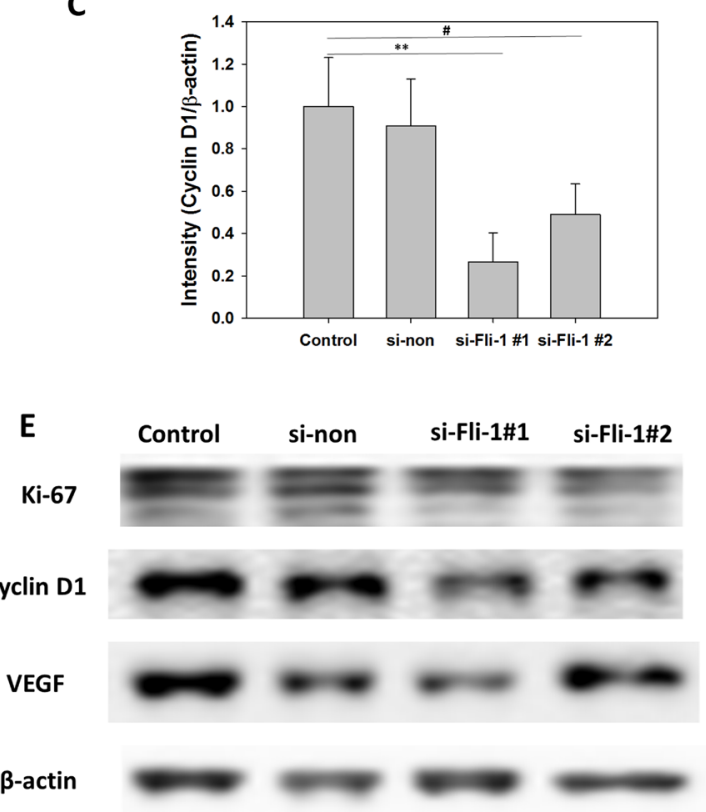

G

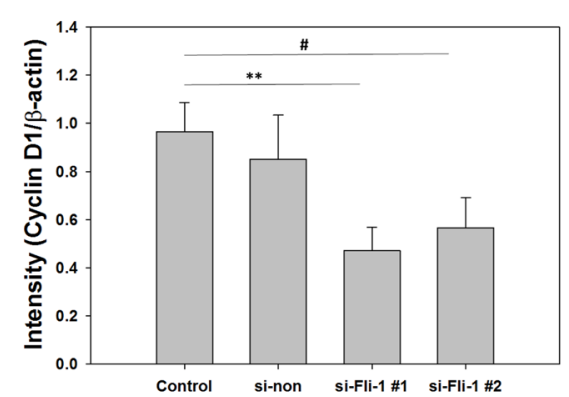

D

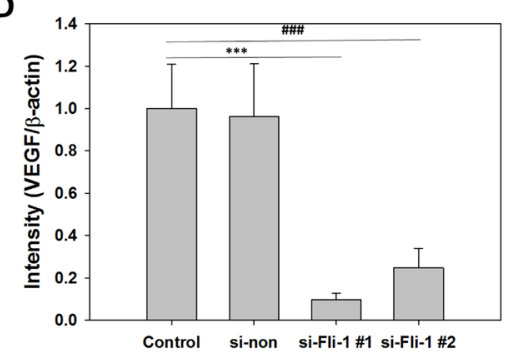

$\mathbf{F}$

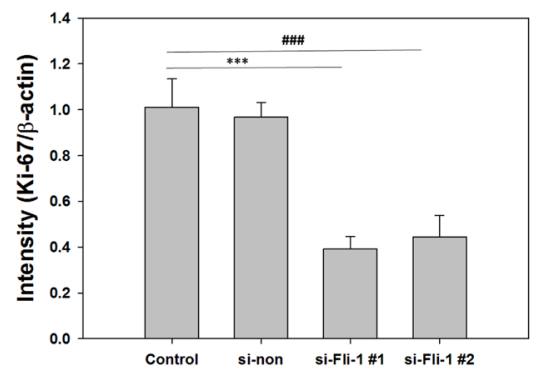

H

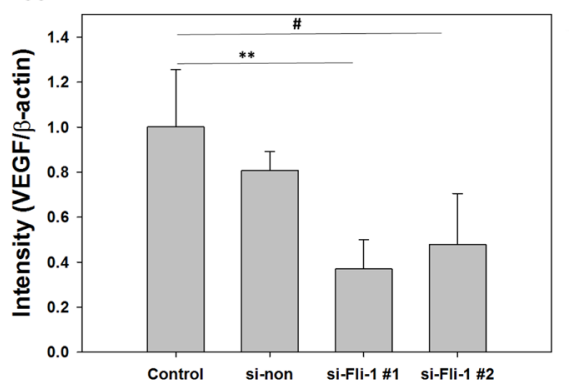

Figure 9: Expression levels of Ki-67, vascular endothelial growth factor (VEGF), and cyclin D1 proteins in control, non-siRNA-treated, and Fli-1 siRNA-treated cells in GBM8401 cells and U87MG cells. (A) Western blot to assess Ki67, VEGF, and cyclin D1 expression in GBM8401 cells. Relative protein expression levels of (B) Ki-67, (C) VEGF, and (D) cyclin D1 GBM8401 cells. (E) Western blot to assess Ki-67, VEGF, and cyclin D1 expression in U87MG cells. Relative protein expression levels of (F) Ki-67, (G) VEGF, and (H) cyclin D1 U87MG cells. $\left({ }^{*} P<0.05,{ }^{* *} P<0.01\right.$, and ${ }^{* * *} P<0.001$ compared with si-Fli-1 $\# 1$; ${ }^{\#} P<0.05$, ${ }^{\# \#} P$ $<0.01$, and ${ }^{\# \#} P<0.001$ compared with si-Fli-1 \#2). 
Previous studies have defined a role for Fli-1 in erythroleukemic cell growth and differentiation. One such study demonstrated the binding of Fli-1 to an ETS consensus site in the context of cell growth maintenance [36]. ETS family transcription factors regulate the expression of oncogenes, tumor suppressor genes, and other genes associated with vessel formation, invasion, and metastasis, and their expression often correlates with poor survival in some types of cancers [21, 37-39]. Fli-1 plays a critical role in normal development, hematopoiesis and oncogenesis by functioning as both transcriptional activator and repressor [34, 40, 41]. Knocking-down Fli1 expression in erythroleukemic cells leads to a marked growth inhibition and cell death, demonstrating a possible therapeutic approach to induce tumor suppression [42, 43]. The observation of strong Fli-1 expression in adenoid-like differentiated NPC suggests that NPC cancer cells might develop adenoid-like endothelium consequent to Fli-1mediated gene expression. The EWS/FLI-1 fusion product promotes tumor angiogenesis by upregulating VEGF-A expression [34], and in our study, Fli-1 knockdown attenuated the expression of Ki-67, VEGF, and cyclin D1 proteins. These data supported a role for Fli-1 in the regulation of tumor progression.

\section{MATERIALS AND METHODS}

\section{Patients}

For this study, we selected patients with astrocytoma who were treated at the Neurosurgery Department of Chung Ho Hospital, Kaohsiung Medical University between 2002 and 2014. Patients who were diagnosed by biopsy only or had incomplete medical records, no follow-up data, low-quality pathological results, or poor immunohistochemical staining were excluded. A total of 109 patients were selected for this study.

\section{Immunohistochemical staining}

Three-micrometer sections were cut from formalinfixed, paraffin-embedded tissue samples collected from each patient. Sections were deparaffinized, rehydrated, and autoclaved at $121^{\circ} \mathrm{C}$ for $10 \mathrm{~min}$ in Target Retrieval solution, pH 6.0 (S2369; Dako, Glostrup, Denmark) for antigen retrieval. After letting the sections rest for $20 \mathrm{~min}$ at room temperature, $3 \%$ hydrogen peroxide was applied for $5 \mathrm{~min}$ at room temperature to block endogenous peroxidase. After washing twice with Tris buffer, the sections were incubated with a Fli-1 antibody (1:200 dilution) for 1 hour at room temperature. After washing twice with Tris buffer, the sections were incubated with a secondary horseradish peroxidase-conjugated antibody for $30 \mathrm{~min}$ at room temperature. Finally, the slides were incubated in 3,3-diaminobenzidine (K5007; Dako) for 5 min, counterstained with Mayer's hematoxylin for $90 \mathrm{sec}$, and mounted with Malinol.

Immunohistochemical staining results were classified as low-level expression and high-level expression. Scores, which represented the proportions of positively stained tumor cells, were determined as follows: 0 , no positive tumor cells; $1,<10 \%$ positive cells; $2,10-50 \%$ positive cells; and 3, $>50 \%$ positive cells. The staining intensity was classified as 0 , no staining; 1 , weak staining; 2, moderate staining; or 3, strong staining. The staining index (SI) was calculated by multiplying the intensity and percentage of positive tumor cells in each sample to yield possible scores of $0,1,2,3,4,6$, and 9 . We set a total score of 4 as a cut-off; in other words, $\geq 4$ was considered high Fli-1 expression, and $<3$ was considered low expression.

\section{Cell culture and Fli-1 siRNA transfection}

All cell lines were incubated at $37^{\circ} \mathrm{C}$ in an atmosphere of $5 \% \mathrm{CO}_{2}$. The cell lines GBM8401 and GB8901 were cultured in RPMI medium supplemented with $10 \%$ fetal bovine serum (FBS). U87-MG and SVGp12 were cultured in modified Eagle's medium (MEM) supplemented with 10\% FBS. G5T was cultured in Dulbecco's MEM (DMEM) medium supplemented 10\% FBS. GBM8401, GBM8901, U87-MG, and G5T were isolated from GBM patients; SVGp12 was isolated from normal tissue and used as a normal control.

siRNA transfection of astrocytoma cells was achieved using DharmaFECT ${ }^{\mathrm{TM}}$ Transfection Reagents (Dharmacon, Lafayette, CO, USA) and human Fli1 siRNA constructs (Sigma, St. Louis, MO, USA) with the following sequences: Fli-1 siRNA\#1 5'-GUUCACUGCUGGCCUAUAA-3' and; Fli-1 SiRNA\#2 5'-CACAAACGAUCAGUAACAA-3'. A 5- $\mu \mathrm{M}$ Fli-1 siRNA concentration was used for transfection. Following transfection with siRNA, cells were cultured for 1 days before use. Fli-1 protein expression levels were detected by western blot analysis.

\section{Proliferation assay}

Cells were suspended in culture medium containing $10 \%$ FBS and placed in a 24-well plate at an approximate density of $1 \times 10^{4}$ cells per $0.5 \mathrm{ml}$ of medium per each well. The cells were incubated as described above for 24 $\mathrm{h}, 48 \mathrm{~h}$, and $72 \mathrm{~h}$ with 3-(4,5-dimethylthiazol-2-yl)-2,5diphenyltetrazolium bromide (MTT) assay.

\section{Migration assay}

Cell migration was evaluated using a wound healing assay (80209; ibidi GmbH, Martinsried, Germany). For this assay, 6-well plates were coated with culture-inserts and incubated at $37^{\circ} \mathrm{C}$ for $12 \mathrm{~h}$. Cells were seeded $70 \mu \mathrm{l}$ at a density of $5 \times 10^{5}$ cell $/ \mathrm{ml}$ and incubated for 12 hours 
and 24 hours with $10 \mu \mathrm{g} / \mathrm{ml}$ mitomycin C (Sigma) after 48 hours prior to siRNA transfection.

\section{Invasion assay}

In vitro cell invasion assays were performed using Transwell chambers (COR3452; CORNING, Corning, NY, USA). Cells after siRNA transfection were seeded at a density of 1,000 cells per insert, and the lower chamber of each Transwell was filled with $2 \mathrm{ml}$ of medium containing $10 \% \mathrm{FBS}$. After a $24-\mathrm{h}$ incubation, cells remaining on the upper surfaces of the Transwell membranes were removed using cotton swabs. Cells that had invaded across the membranes to the bottom of the insert were fixed, stained, photographed, and quantified by counting the numbers of cells in 6 random high-powered fields.

\section{Cytoplasmic and nuclear protein extraction}

Cells were detached from culture plates using trypsin, and centrifuged at $500 \mathrm{~g}$ for $3 \mathrm{~min}$ to obtain cell pellets. Each pellet was mixed with $200 \mu \mathrm{l}$ of CER, mixed, and vortexed at a high speed for $15 \mathrm{~s}$, followed by a 30min incubation on ice. The mixture was vortexed again at a high speed for $5 \mathrm{~s}$ and centrifuged at $16000 \mathrm{~g}$ for 10 min at $4^{\circ} \mathrm{C}$, after which the supernatant was removed and reserved as the cytoplasmic protein fraction. Next, $50 \mu \mathrm{l}$ of NER was added to each pellet, followed by thorough high-speed vortexing for 15 seconds and incubation on ice for 30 minutes. During this incubation, the mixtures were vortexed for $20 \mathrm{~s}$ at a high speed every $5 \mathrm{~min}$, followed by centrifugation at $16000 \mathrm{~g}$ for $30 \mathrm{mins}$ at $4^{\circ} \mathrm{C}$. The resulting supernatant was reserved as the nuclear protein fraction.

\section{Western blotting}

All samples were lysed in $200 \mu$ of lysis buffer. A total of $50 \mu \mathrm{g}$ of protein per sample was loaded into the wells of a sodium dodecyl sulfate-polyacrylamide gel and subjected to electrophoresis at $50 \mathrm{~V}$ for $4 \mathrm{~h}$. The separated proteins were subsequently transferred to PVDF membranes. After incubation for $1 \mathrm{~h}$ in blocking buffer, the membranes were incubated with primary antibodies [Fli-1 (554266, 1:500; BD Pharmingen, San Diego, CA, USA), Ki-67 (1:1000; Dako), cyclin D1 (RM-9104, 1:500; Thermo, UK), and $\beta$-actin (60008-1-lg, 1:20,000; proteintech, USA)] for $2 \mathrm{~h}$ at room temperature. Subsequently, the membranes were incubated with secondary antibodies [goat anti-rabbit (AP132P, 1:5000; Millipore, Billerica, MA, USA) and goat anti-mouse (AP124P, 1:5000; Millipore)] for $90 \mathrm{~min}$. Enhanced chemiluminescence solution (Western Lightning, 20514621; Perkin Elmer, Waltham, MA, USA) and a MiniChemi ${ }^{\mathrm{TM}}$ imaging and analysis system (Beijing Sage Creation, Beijing, China) were used to detect specific protein bands.

\section{Data analysis}

SPSS 19.0 software (SPSS, Inc., Chicago, IL, USA) was used for the statistical analysis. The chisquare test was performed to determine the existence of correlations between $\mathrm{Sp} 1$ protein expression and specific clinicopathologic parameters. The Kaplan-Meier method and log-rank test were used for the survival rate analysis. Multivariate Cox regression analyses were used to verify the independent effect of each variable evaluated in this study. A one-way analysis of variance (ANOVA) was used to compare the results of the proliferation, migration, and invasion assays. For all analyses, a $p$ value $<0.05$ was considered statistically significant.

\section{CONCLUSION}

In summary, Fli-1 was expressed in the nuclei of astrocytoma cells. A high level of Fli-1 expression was detected in high-grade astrocytomas and was associated with poor prognosis, and both the univariate and multivariate analyses identified an association of Fli1 with the overall survival duration. Fli-1 knockdown attenuated the proliferation, migration, and invasion of astrocytoma cells and downregulated the expression of $\mathrm{Ki}$ 67, VEGF, and cyclin D1. These results suggest that the potential use of Fli-1 as a prognostic biomarker in patients with astrocytoma.

\section{ACKNOWLEDGMENTS}

This study was supported by a grant from the Kaohsiung Medical University Hospital (KMUH-1022R16 and KMUH103-3R18).

\section{CONFLICTS OF INTEREST}

The authors declare no conflicts of interest.

\section{REFERENCES}

1. Louis DN, Ohgaki H, Wiestler OD, Cavenee WK, Burger PC, Jouvet A, Scheithauer BW, Kleihues P. The 2007 WHO classification of tumours of the central nervous system. Acta Neuropathol. 2007; 114:97-109.

2. Stupp R, Hegi ME, Mason WP, van den Bent MJ, Taphoorn MJ, Janzer RC, Ludwin SK, Allgeier A, Fisher B, Belanger K, Hau P, Brandes AA, Gijtenbeek J, et al. Effects of radiotherapy with concomitant and adjuvant temozolomide versus radiotherapy alone on survival in glioblastoma in a randomised phase III study: 5-year analysis of the EORTCNCIC trial. Lancet Oncol. 2009; 10:459-466.

3. Omuro A, DeAngelis LM. Glioblastoma and other malignant gliomas: a clinical review. JAMA. 2013; 310:1842-1850. 
4. Liang H, Mao X, Olejniczak ET, Nettesheim DG, Yu L, Meadows RP, Thompson CB, Fesik SW. Solution structure of the ets domain of Fli-1 when bound to DNA. Nat Struct Biol. 1994; 1:871-875.

5. Liang H, Olejniczak ET, Mao X, Nettesheim DG, Yu L, Thompson CB, Fesik SW. The secondary structure of the ets domain of human Fli-1 resembles that of the helix-turnhelix DNA-binding motif of the Escherichia coli catabolite gene activator protein. Proc Natl Acad Sci U S A. 1994; 91:11655-11659.

6. Ben-David Y, Bernstein A. Friend virus-induced erythroleukemia and the multistage nature of cancer. Cell. 1991; 66:831-834.

7. Maroulakou IG, Bowe DB. Expression and function of Ets transcription factors in mammalian development: a regulatory network. Oncogene. 2000; 19:6432-6442.

8. Oikawa T, Yamada T. Molecular biology of the Ets family of transcription factors. Gene. 2003; 303:11-34.

9. Davidson B, Reich R, Goldberg I, Gotlieb WH, Kopolovic J, Berner A, Ben-Baruch G, Bryne M, Nesland JM. Ets-1 messenger RNA expression is a novel marker of poor survival in ovarian carcinoma. Clin Cancer Res. 2001; 7:551-557.

10. Oikawa T. ETS transcription factors: possible targets for cancer therapy. Cancer Sci. 2004; 95:626-633.

11. Hahm KB, Cho K, Lee C, Im YH, Chang J, Choi SG, Sorensen PH, Thiele CJ, Kim SJ. Repression of the gene encoding the TGF-beta type II receptor is a major target of the EWS-FLI1 oncoprotein. Nat Genet. 1999; 23:222-227.

12. Nakatani F, Tanaka $\mathrm{K}$, Sakimura $\mathrm{R}$, Matsumoto $\mathrm{Y}$, Matsunobu T, Li X, Hanada M, Okada T, Iwamoto Y. Identification of p21WAF1/CIP1 as a direct target of EWS-Flil oncogenic fusion protein. J Biol Chem. 2003; 278:15105-15115.

13. Melet F, Motro B, Rossi DJ, Zhang L, Bernstein A. Generation of a novel Fli-1 protein by gene targeting leads to a defect in thymus development and a delay in Friend virus-induced erythroleukemia. Mol Cell Biol. 1996; 16:2708-2718.

14. Truong AH, Ben-David Y. The role of Fli-1 in normal cell function and malignant transformation. Oncogene. 2000; 19:6482-6489.

15. Spyropoulos DD, Pharr PN, Lavenburg KR, Jackers $P$, Papas TS, Ogawa M, Watson DK. Hemorrhage, impaired hematopoiesis, and lethality in mouse embryos carrying a targeted disruption of the Fli1 transcription factor. Mol Cell Biol. 2000; 20:5643-5652.

16. Liu F, Walmsley M, Rodaway A, Patient R. Fli1 acts at the top of the transcriptional network driving blood and endothelial development. Curr Biol. 2008; 18:1234-1240.

17. Lakhanpal GK, Vecchiarelli-Federico LM, Li YJ, Cui JW, Bailey ML, Spaner DE, Dumont DJ, Barber DL, Ben-David Y. The inositol phosphatase SHIP-1 is negatively regulated by Fli-1 and its loss accelerates leukemogenesis. Blood. 2010; 116:428-436.

18. Cui JW, Vecchiarelli-Federico LM, Li YJ, Wang GJ, BenDavid Y. Continuous Fli-1 expression plays an essential role in the proliferation and survival of F-MuLV-induced erythroleukemia and human erythroleukemia. Leukemia. 2009; 23:1311-1319.

19. Takigami I, Ohno T, Kitade Y, Hara A, Nagano A, Kawai G, Saitou M, Matsuhashi A, Yamada K, Shimizu K. Synthetic siRNA targeting the breakpoint of EWS/Fli-1 inhibits growth of Ewing sarcoma xenografts in a mouse model. Int J Cancer. 2011; 128:216-226.

20. Zhang J, Guo H, Zhang H, Wang H, Qian G, Fan X, Hoffman AR, Hu JF, Ge S. Putative tumor suppressor miR145 inhibits colon cancer cell growth by targeting oncogene Friend leukemia virus integration 1 gene. Cancer. 2011; 117:86-95.

21. Torlakovic EE, Slipicevic A, Florenes VA, Chibbar R, DeCoteau JF, Bilalovic N. Fli-1 expression in malignant melanoma. Histol Histopathol. 2008; 23:1309-1314.

22. Song W, Hu L, Li W, Wang G, Li Y, Yan L, Li A, Cui J. Oncogenic Fli-1 is a potential prognostic marker for the progression of epithelial ovarian cancer. BMC Cancer. 2014; $14: 424$.

23. Song W, Zhang T, Li W, Mu R, Zhang L, Li Y, Jin B, Wang N, Li A, Cui J. Overexpression of Fli-1 is associated with adverse prognosis of endometrial cancer. Cancer Invest. 2015; 33:469-475.

24. Scheiber MN, Watson PM, Rumboldt T, Stanley C, Wilson RC, Findlay VJ, Anderson PE, Watson DK. FLI1 expression is correlated with breast cancer cellular growth, migration, and invasion and altered gene expression. Neoplasia. 2014; 16:801-813.

25. Liang X, Shi D, Yun J, Mao Y, Ouyang P, Su Z, Fu J, Hou J, Deng W, Xie F. Friend leukemia virus integration 1 expression has prognostic significance in nasopharyngeal carcinoma. Transl Oncol. 2014; 7:493-502.

26. Pereira R, Quang CT, Lesault I, Dolznig H, Beug H, Ghysdael J. FLI-1 inhibits differentiation and induces proliferation of primary erythroblasts. Oncogene. 1999; 18:1597-1608.

27. Bujor AM, Asano Y, Haines P, Lafyatis R, Trojanowska M. The c-Abl tyrosine kinase controls protein kinase Cdeltainduced Fli-1 phosphorylation in human dermal fibroblasts. Arthritis Rheum. 2011; 63:1729-1737.

28. Eisbacher M, Holmes ML, Newton A, Hogg PJ, Khachigian LM, Crossley M, Chong BH. Protein-protein interaction between Fli-1 and GATA-1 mediates synergistic expression of megakaryocyte-specific genes through cooperative DNA binding. Mol Cell Biol. 2003; 23:3427-3441.

29. Starck J, Cohet N, Gonnet C, Sarrazin S, Doubeikovskaia Z, Doubeikovski A, Verger A, Duterque-Coquillaud M, Morle F. Functional cross-antagonism between 
transcription factors FLI-1 and EKLF. Mol Cell Biol. 2003; 23:1390-1402.

30. Heo SH, Choi YJ, Ryoo HM, Cho JY. Expression profiling of ETS and MMP factors in VEGF-activated endothelial cells: role of MMP-10 in VEGF-induced angiogenesis. J Cell Physiol. 2010; 224:734-742.

31. Cuda J, Mirzamani N, Kantipudi R, Robbins J, Welsch MJ, Sundram UN. Diagnostic utility of Fli-1 and D2-40 in distinguishing atypical fibroxanthoma from angiosarcoma. Am J Dermatopathol. 2013; 35:316-318.

32. Brown JG, Folpe AL, Rao P, Lazar AJ, Paner GP, Gupta R, Parakh R, Cheville JC, Amin MB. Primary vascular tumors and tumor-like lesions of the kidney: a clinicopathologic analysis of 25 cases. Am J Surg Pathol. 2010; 34:942-949.

33. Gill R, O'Donnell RJ, Horvai A. Utility of immunohistochemistry for endothelial markers in distinguishing epithelioid hemangioendothelioma from carcinoma metastatic to bone. Arch Pathol Lab Med. 2009; 133:967-972.

34. Nagano A, Ohno T, Shimizu K, Hara A, Yamamoto T, Kawai G, Saitou M, Takigami I, Matsuhashi A, Yamada K, Takei Y. EWS/Fli-1 chimeric fusion gene upregulates vascular endothelial growth factor-A. Int J Cancer. 2010; 126:2790-2798.

35. Shaked Y, Cervi D, Neuman M, Chen L, Klement G, Michaud CR, Haeri M, Pak BJ, Kerbel RS, BenDavid Y. The splenic microenvironment is a source of proangiogenesis/inflammatory mediators accelerating the expansion of murine erythroleukemic cells. Blood. 2005; 105:4500-4507.

36. Tamir A, Howard J, Higgins RR, Li YJ, Berger L, Zacksenhaus E, Reis M, Ben-David Y. Fli-1, an Ets-related transcription factor, regulates erythropoietin-induced erythroid proliferation and differentiation: evidence for direct transcriptional repression of the $\mathrm{Rb}$ gene during differentiation. Mol Cell Biol. 1999; 19:4452-4464.
37. Riggi N, Suva ML, Suva D, Cironi L, Provero P, Tercier S, Joseph JM, Stehle JC, Baumer K, Kindler V, Stamenkovic I. EWS-FLI-1 expression triggers a Ewing's sarcoma initiation program in primary human mesenchymal stem cells. Cancer Res. 2008; 68:2176-2185.

38. Sakurai T, Kondoh N, Arai M, Hamada J, Yamada T, Kihara-Negishi F, Izawa T, Ohno H, Yamamoto M, Oikawa T. Functional roles of Fli-1, a member of the Ets family of transcription factors, in human breast malignancy. Cancer Sci. 2007; 98:1775-1784.

39. Quick CM, Smoller BR, Hiatt KM. Fli-1 expression in mycosis fungoides. J Cutan Pathol. 2006; 33:642-645.

40. Mhawech-Fauceglia P, Herrmann FR, Bshara W, Odunsi K, Terracciano L, Sauter G, Cheney RT, Groth J, Penetrante R, Mhawech-Fauceglia P. Friend leukaemia integration-1 expression in malignant and benign tumours: a multiple tumour tissue microarray analysis using polyclonal antibody. J Clin Pathol. 2007; 60:694-700.

41. Shintani S, Hamakawa H, Nakashiro K, Shirota T, Hatori M, Tanaka M, Kuroshita Y, Kurokawa Y. Friend leukaemia insertion (Fli)-1 is a prediction marker candidate for radiotherapy resistant oral squamous cell carcinoma. Int $\mathrm{J}$ Oral Maxillofac Surg. 2010; 39:1115-1119.

42. Zhou GQ, Tang LL, Mao YP, Chen L, Li WF, Sun Y, Liu LZ, Li L, Lin AH, Ma J. Baseline serum lactate dehydrogenase levels for patients treated with intensitymodulated radiotherapy for nasopharyngeal carcinoma: a predictor of poor prognosis and subsequent liver metastasis. Int J Radiat Oncol Biol Phys. 2012; 82:e359-365.

43. Lee SL, Rouhi P, Dahl Jensen L, Zhang D, Ji H, Hauptmann G, Ingham P, Cao Y. Hypoxia-induced pathological angiogenesis mediates tumor cell dissemination, invasion, and metastasis in a zebrafish tumor model. Proc Natl Acad Sci U S A. 2009; 106:19485-19490. 